E3S Web of Conferences 1, 10002 (2013)

DOI: $10.1051 / \mathrm{e} 3$ sconf/20130110002

(c) Owned by the authors, published by EDP Sciences, 2013

\title{
Assessment and Remediation of Lead Contamination in Esperance, Western Australia.
}

\author{
P. B. McCafferty ${ }^{1}$, M. Devenish ${ }^{2}$, H. M. Burton ${ }^{1}$, M. Jackson, ${ }^{2}$ M. North ${ }^{1}$ and W. Winchester ${ }^{2}$ \\ ${ }^{1}$ ChemCentre, Scientific Services Division, Perth Western Australia. pmccafferty@chemcentre.wa.gov.au \\ ${ }^{2}$ Department of Transport (Western Australia), Perth Western Australia.
}

\begin{abstract}
This paper presents an overview of a lead contamination event that occurred over a period of time in and around Esperance, Western Australia. It also describes the scientific developments necessary to effect the large scale cleanup of lead contamination in the town. This work was possibly the largest environmental cleanup of its kind ever undertaken in Australia. The work undertaken involved characterisation and assessment of the extent of contamination, development of remediation techniques and validation procedures to ensure that that this cleaning had been successful.
\end{abstract}

Key words: Heavy metals, lead, large area remediation, contamination

\section{Introduction}

Esperance is a community of approximately 15,000 people, who have traditionally been involved with fishing and agricultural export (wheat and sheep). Tourism is another significant source of income, with Esperance beaches being internationally renowned for their pristine white sands and abundant wildlife. Esperance experiences strong, seasonal and reliable winds. It was the first site in Western Australia selected for wind based power generation.

A deposit of cerussite (mineral lead carbonate) was mined by Magellan Metals (a subsidiary of Ivernia Inc, a multinational mining company) near Wiluna $900 \mathrm{~km}$ north of Esperacne in the remote midwest region of Western Australia, Australia. The resulting lead carbonate concentrate was transported as a bulk commodity by road and rail prior to being exported through the Port of Esperance between July 2005 and March 2007. This involved a journey of approximately $900 \mathrm{~km}$ from the mine to the Port. Lead as a fine dust escaped during the transport, storage and loading processes at the Port, leading to widespread contamination across the town.

The Esperance community was understandably outraged at the lead contamination of their town. The media coverage of the incident was dramatic and persistent with many images of dead birds in Esperance in the national media. One report (Department of Environment and Conservation, 2007) suggested that up to 4,000 birds had died as a result of lead poisoning over a relatively short time period. The community was concerned about the impact of the lead on human health and the previously pristine environment. They were also worried about the safety of their rain water (which was collected for drinking), their home grown fruit and vegetables and locally caught seafood. Parents of young children were especially concerned that the lead contamination of their homes and environment had impacted on the blood lead levels in their children and that it would have a lasting impact on intellectual development of their children.

The bulk commodity handling techniques that resulted in the lead contamination also resulted in elevated levels of nickel, which was exported by several companies and from different sources through Esperance. This discussion will be limited to the lead-related issue only.

Lead is a known cumulative toxin that can affect the central nervous system. It is also known that children exposed to levels of lead can experience neuro-developmental issues. Infants and those with impaired kidney or liver function may be particularly at risk. The World Health Organisation, WHO (WHO, 1995) advocate an action level of $10 \mu \mathrm{g} / \mathrm{dl}$ as requiring intervention in children. Of the 2,695 individuals (adults and children) who were tested across the Esperance townsite, 31 were found to have blood lead levels above $10 \mu \mathrm{g} / \mathrm{dl}$. Of these 7 were children under 5 years of age. 


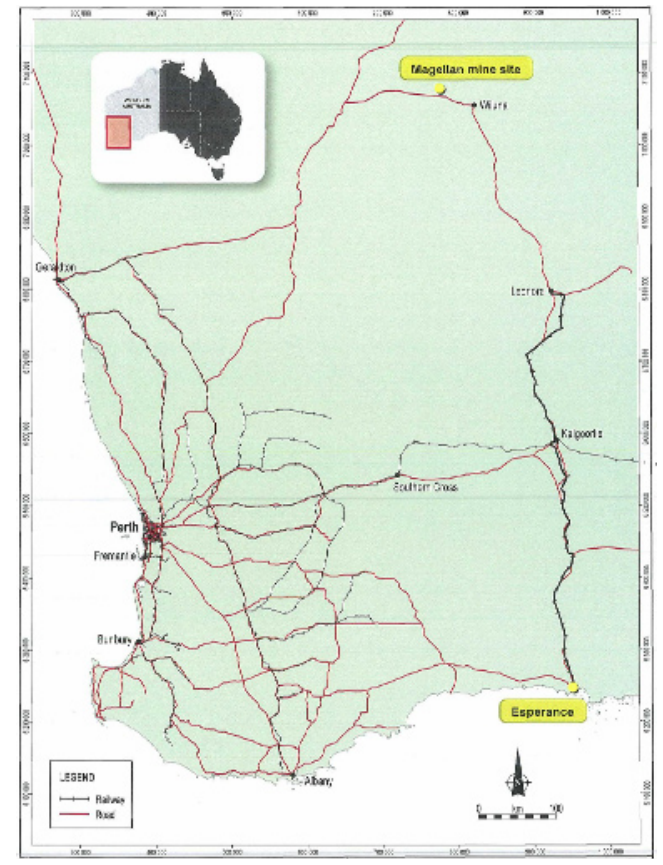

Figure 1. Map showing the location of the mine site near Wiluna and Esperance, south east coast of Western Australia.

There is growing recognition that lower levels of blood lead may have more subtle effects on neurobehaviors and cognition in children (Jones, 2007) and that authorities are seeking to amend this level downwards (Rhoads, et al, 2012). There is good reason to minimize lead exposure where practicable.

\section{Materials and Methods}

When the lead contamination became apparent, the Western Australian Government established the Esperance Cleanup and Recovery Project (ECRP) to coordinate the cleanup response. The Department of Transport (who had legislative governance over the Port) was appointed as the agency to manage the project. The mission of the ECRP was to undertake a comprehensive assessment and cleanup of the lead contamination, where it was found to exceed agreed.

Contamination and subsequent remediation of the type and scale as that experienced in Esperance is without precedent in Australia (and perhaps the world).

A trial program of assessment and cleanup of 35 selected trial homes in Esperance was initially undertaken. This provided a valuable mechanism of tackling those premises where the lead contamination may have been predicted to be highest (for example those in close proximity to the port). It also provided a means of developing techniques and standards upon which the remaining homes in Esperance could be assessed and remediated. This resulted in a series of peer reviewed assessment and cleanup techniques being developed. Where possible, these were referenced to internationally accepted guidelines (e.g. drinking water, blood lead, etc).
Where reference to applicable standards was not possible the ECRP team drafted suitable standards and had these scrutinized by a panel of experts nationally and in some cases internationally. Community consultation also provided a valuable means of cross-referencing against public expectations.

Techniques for the valid collection of samples including blood, soil, dusts, water, sediments, soils and biota were employed. Analytical techniques were employed to determine the extent and levels of the contamination. These techniques were subjected to ISO 9001 and NATA (National Association of Testing Authorities, Australia) accreditation. The sampling program resulted in more than 120,000 samples being assessed in the field. Techniques including inductively coupled plasma (atomic emission and mass spectrometry, ICP-AES and ICP-MS) and x-ray fluorescence (XRF) were employed. A field portable XRF provided a very useful tool for 'real-time' monitoring of solid samples (soil, surface, dust) in the field and for screening samples prior to laboratory analysis. A trial of a anodic stripping voltammetry (ASV) instrument to provide a field based method for lead in water samples was also undertaken (McCafferty and Wajrak, 2010).

Utilisation of GPS (global positioning system) logging of samples and mapping of results was undertaken (Figure 2). Overlaying the results for multiple sample types provided a powerful tool to assist with determining the extent of contamination. Methods were developed to clean houses (both internally and externally), rainwater tanks, publicly accessible equipment (e.g. playground and park equipment) and soil areas. Where applicable, techniques for the appropriate disposal of high lead containing material was also developed as part of the overall remediation. Importantly, the progress of all of this activity was communicated and explained to the Esperance community at every stage.

\section{Results and Discussion}

Significantly, ICP-MS lead isotopic 'fingerprint' techniques, were used to determine the likely source of the lead. This technique was a key tool to confirm that the source of the lead contamination was from lead originating from the Magellan's Wiluna mine, rather than from other sources. As lead is ubiquitous throughout most environments (historical vehicle emissions, lead paints, lead stearate plasticisers, etc.) this technique was useful in determining the likely vectors of lead contamination.

Lead has four naturally occurring stable isotopes, ${ }^{204} \mathrm{~Pb},{ }^{206} \mathrm{~Pb},{ }^{207} \mathrm{~Pb},{ }^{208} \mathrm{~Pb}$. The average natural abundance of these isotopes is approximately $1.4 \%, 24.1 \%, 22.1 \%$ and $52.4 \%$ respectively; however the actual concentration of each of these isotopes is dependent on the source of the lead. The ${ }^{206} \mathrm{~Pb},{ }^{207} \mathrm{~Pb},{ }^{208} \mathrm{~Pb}$ isotopes are products of the radioactive decay from other elements such as uranium and thorium. The ${ }^{204} \mathrm{~Pb}$ isotope is not a product of decay and is thus useful as a reference. 


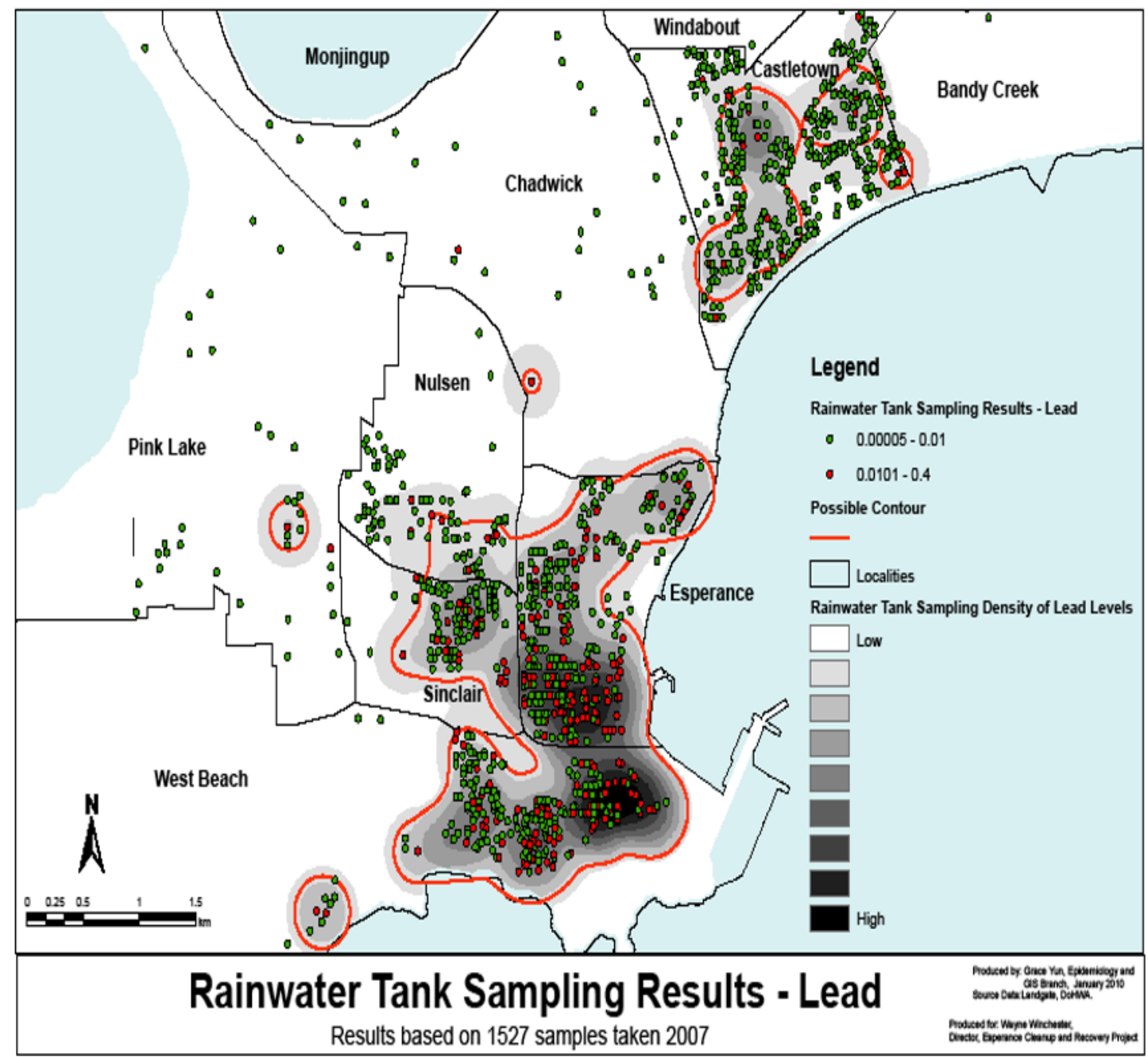

Figure 2. Results of analysis of rainwater tank samples from Esperance, WA with contour of concentration

The progression of this decay, determined by the isotope ratios, can give an indication of the geological age of the lead ore deposit and the origin of the lead. Hence, geologically old deposits like that at Broken Hill (north west New South Wales, Australia) have a ratio of ${ }^{206} \mathrm{~Pb}:{ }^{204} \mathrm{~Pb}$ that are different to that of younger ore bodies such as those that might be found in western Tasmania, Australia. Approximately 1500 samples from Esperance were analysed for their lead isotope 'fingerprint'.

Dust deposition gauges and high volume dust collection samplers were located around the town. These together with resampling 'cleaned' areas and periodic seasonal vegetation sampling provided a means of assessing the possible redistribution of deposited lead.

\section{Conclusion}

The assessment and subsequent remediation of the widespread lead contamination of Esperance, Western Australia has been achieved via a multi-skilled approach, employing the professional capabilities of analytical chemists, environmental health practitioners, doctors, epidemiologists, and members of the community. The techniques and lessons learnt in Esperance, Western Australia have been developed to specifically address the issue of lead contamination as it applies to this environment. While caution must be exercised prior to applying these techniques (without modification) to other environments the processes of sampling, analysis and community engagement may provide a valuable template for the assessment and remediation of other environments.

\section{Acknowledgements}

The authors wish to thank the Premier of Western Australia for permission to present this paper, the Director Generals and Chief Executive Officers of ChemCentre (Western Australia), Department of Transport (Western Australia), Department of Health (Western Australia) and the Department of Environment and Conservation (Western Australia). Thanks also go to the many staff of each of these organisations, members of the Esperance Cleanup and Recovery Project team and 
the community of Esperance, Western Australia.

\section{References}

DEC, Department of Environment and Conservation, Western Australia. "The bird death investigation. Fact Sheet 1.” April 2007.

McCafferty PB and Wajrak M. "Validation of a portable Digital Voltammeter, PDV6000+ Instrument for Detection of Lead in Rain Water Sample in
Esperance, Western Australia." 15th International Conference on Heavy Metals in the Environment 19-23 September 2010, Gdansk, Poland.

Rhoads G. G. (Chairman). "Low Level Lead Exposure Harms Children: A Renewed Call of Primary Prevention. Draft Report of the Centre for Disease Control and Prevention. January 2012

World Health Organization, IPCS Environmental Health. Inorganic lead. (Environmental Health Criteria, No. 165). Geneva, 1995. 